ఠ

Open Access Full Text Article

ORIGINAL RESEARCH

\title{
Health status, renal function, and quality of life after multiorgan failure and acute kidney injury requiring renal replacement therapy
}

This article was published in the following Dove Press journal: International Journal of Nephrology and Renovascular Disease 23 May 2016

Number of times this article has been viewed

\section{Robert Faulhaber-Walter ${ }^{1,2}$ Sebastian Scholz',3 Herrmann Haller' Jan T Kielstein ${ }^{1, *}$ Carsten Hafer ${ }^{1,4, *}$ \\ 'Department of Renal and Hypertensive Disease, Medical School Hannover, Hannover, Germany; ${ }^{2}$ Facharztzentrum Aarberg, Waldshut-Tiengen, Germany; ${ }^{3}$ Sanitaetsversorgungszentrum Wunstorf, Wunstorf, Germany; ${ }^{4} \mathrm{HELIOS}$ Klinikum Erfurt, Erfurt, Germany}

*These authors contributed equally to this work

Correspondence: Robert FaulhaberWalter

Facharztzentrum Aarberg, Tannenstrasse 4, 7976 I Waldshut-Tiengen, Germany

$\mathrm{Tel}+49775191680$

Fax +49 775। 916829

Email rofaulhaber@web.de
Background: Critically ill patients with acute kidney injury (AKI) in need of renal replacement therapy (RRT) may have a protracted and often incomplete rehabilitation. Their long-term outcome has rarely been investigated.

Study design: Survivors of the HANnover Dialysis OUTcome (HANDOUT) study were evaluated after 5 years for survival, health status, renal function, and quality of life (QoL). The HANDOUT study had examinded mortality and renal recovery of patients with AKI receiving either standard extendend or intensified dialysis after multi organ failure.

Results: One hundred fifty-six former HANDOUT participants were analyzed. In-hospital mortality was $56.4 \%$. Five-year survival after AKI/RRT was 40.1\% (86.5\% if discharged from hospital). Main causes of death were cardiovascular complications and sepsis. A total of 19 survivors presented to the outpatient department of our clinic and had good renal recovery (mean estimated glomerular filtration rate $72.5 \pm 30 \mathrm{~mL} / \mathrm{min} / 1.73 \mathrm{~m}^{2}$; mean proteinuria $89 \pm 84 \mathrm{mg} / \mathrm{d}$ ). One person required maintenance dialysis. Seventy-nine percent of the patients had a pathological kidney sonomorphology. The Charlson comorbidity score was $2.2 \pm 1.4$ and adjusted for age $3.3 \pm 2.1$ years. Numbers of comorbid conditions averaged $2.38 \pm 1.72$ per patient (heart failure [52\%] $>$ chronic kidney disease/myocardial infarction [each 29\%]). Median 36-item short form health survey (SF-36 $\left.{ }^{\mathrm{TM}}\right)$ index was 0.657 ( 0.69 physical health/0.66 mental health). Quality-adjusted life-years after 5 years were 3.365 .

Conclusion: Mortality after severe AKI is higher than short-term prospective studies show, and morbidity is significant. Kidney recovery as well as general health remains incomplete. Reduction of QoL is minor, and social rehabilitation is very good. Affectivity is heterogeneous, but most patients experience emotional well-being. In summary, AKI in critically ill patients leads to incomplete rehabilitation but acceptable QoL after 5 years.

Keywords: acute kidney injury, renal replacement therapy, QoL, HANDOUT, multiorgan failure, long-term follow-up

\section{Background}

Acute kidney injury (AKI) is an independent risk factor for high mortality, with an increasing incidence in intensive care unit (ICU) patients and high rates of renal replacement therapy (RRT). ${ }^{1,2}$ Next to the patient's individual health problem, the AKI/ RRT leads to a high burden of socioeconomic cost to health care systems. Already, AKI in very early stages increased the cost of in-hospital treatment., ${ }^{3,4}$ The cost per quality-adjusted life-year (QALY) saved by initiating dialysis and continuing aggressive care in hospitalized patients with AKI exceeded the then postulated threshold for 
cost-effectiveness, according to the SUPPORT study. ${ }^{5}$ Cost issues might dominate clinical choices with regard to the use of different dialysis modalities. ${ }^{6}$

A recent meta-analysis reported the in-hospital mortality after AKI as 6\%-80\%. ${ }^{7}$ Nonsurvivors mostly die early in the course of their crisis. ${ }^{1,8-12}$ Most survivors of AKI recover renal function to RRT independence (75\%-98\%). ${ }^{13}$ Hence, AKI survivors appear to be a clinically stable group. However, many data on survival, health status, and quality of life (QoL) after ICU treatment are limited owing to short observational periods. A meta-analysis of 48 studies revealed a median follow-up period of only 3.41 years (0.5-22 years). Only six of the analyzed studies with an available median follow-up included critically ill patients. These particular studies had a median follow-up time of 2.65 years (1-5 years). Only two studies were prospective. ${ }^{7}$ Schiffl and Fischer ${ }^{11}$ complemented data of a 5-year follow-up after AKI, and very recently, Gallagher et $\mathrm{ll}^{14}$ investigated patients from the RENAL study after 4 years. Hence, long-term outcome data of patients after AKI/RRT on ICU are still rare. Although there is some evidence about the rate of end-stage renal disease in the course of AKI $(2 \%-15 \%)$, only few studies have investigated the degree of long-term renal impairment after initial recovery. ${ }^{15-17}$ Moreover, few studies have examined QoL in the long term after severe AKI. ${ }^{13,14,18,19}$ Our study examined the long-term outcome of survivors of AKI/RRT and, for the first time, reported clinical, laboratory, and technical data from a 5-year follow-up outpatient visit.

\section{Methods}

\section{Inclusion criteria}

All participants of the HANnover Dialysis OUTcome (HANDOUT) study were eligible for the follow-up study. HANDOUT was a monocentric, prospective randomized clinical trial conducted from 2003 to 2006 (www.ClinicalTrial.gov ID NCT00529139), comparing intensified, slow long extended dialysis (SLED) vs standard SLED in AKI in critically ill patients (main finding: no benefit of the higher dose) ${ }^{9}$ HANDOUT and this present 5-year follow-up were approved by the Hannover Medical School Ethics Committee (project/ approval \# 2905) and were conducted in accordance with the declaration of Helsinki and German federal guidelines.

\section{Contacting patients}

Three and a half years after inclusion into HANDOUT, the outcome of all participants was analyzed. We applied a diversified strategy to obtain contact information: 1) research of hospital charts, 2) public address and phone registers,
3) contact of family physician, 4) commercial address research agency, and 5) contact of local governmental population registries. All surviving former HANDOUT participants, who could be located, were invited to attend a 5-year followup outpatient study visit at our clinic. Written consent was obtained from all participants.

\section{Follow-up visits, renal function, QoL, and QALY}

All participants were attended by SS (medical student) and $\mathrm{CH}$ or RFW (nephrologists). Their medical history was taken and they were subjected to 1) physical examination, 2) electrocardiography, 3) abdominal ultrasound by two experienced physicians, 4) laboratory panel assessment comprising clinical chemistry, blood count, urinalysis, and 24-hour urine collection to measure proteinuria and creatinine clearance, and 5) physical and mental health self-assessment for QoL using the 36-item short form health survey $\left(\mathrm{SF}-36^{\mathrm{TM}}\right)$ questionnaire. ${ }^{20,21}$ QALY were calculated according to the method of Karlsson et al..$^{22}$ To determine the sum index score, all SF- $36^{\mathrm{TM}}$ variable mean results were adjusted to an optimum value and added up. The index score was then calculated by the equation SF-36 ${ }^{\mathrm{TM}}$ sum index score (variable) $/ 100$ (with variable $=$ either physical health or mental health after defining $0=$ dead or minimal mental health and $1=$ maximal physical and mental health). The costs of the RRT per QALY were calculated with $€ 200$ per single dialysis session, based on the equation:

(Total cost for dialysis [Euro] during HANDOUT/number of 5-year survivors)/QALY. Mortality risk was estimated by Charlson comorbidity score (CCS).

\section{Statistics}

Numerical data were tested for equal variance $f$-test and for significance by two-tailed Student's $t$-test with optional Welch's correction in case of unequal variance. Survival proportions were analyzed by using the Kaplan-Meier curve, censored for either completely lost to follow-up status or at 5 years after the end of the HANDOUT study period. In cases where patients were known to be deceased after the end of HANDOUT but the exact date of death was unknown, the missing dates of dead were interpolated into the whole study population curve.

\section{Results}

\section{Patient flow and feedback}

Of the 156 HANDOUT participants, 65 (41.7\%) died during the study period. The surviving 91 patients were eligible for inclusion into the follow-up study. Of these, 23 more patients 
died after the end of HANDOUT, while still in hospital. The in-hospital mortality of the HANDOUT population was $56.4 \%$. A total of 68 patients survived to hospital discharge were sought for the 5-year follow-up. Of these, five patients could not be located and were grouped as lost to follow-up and censored. The other 63 patients could be located. Of these, 18 were deceased since hospital discharge, and the remaining 45 were invited to participate. No consent could be obtained from 24 patients. Reasons for nonconsent varied. Mostly, no response was received. Others did not specify a reason, and some were not even aware of having had an AKI or even a critical illness in the past. A total of 21 (46.7\%) patients consented to be examined during the study visit 5 years after HANDOUT (Figure 1).

\section{Patient characteristics}

Patients' age ranged from 27 to 78 years (mean 51 years). Seven were female $(33.3 \%)$ and $14(66.7 \%)$ were male. Details are listed in Tables 1 and 2.

\section{Survival}

Analysis of survival proportions after AKI/RRT demonstrated a 1 -year survival rate of $44.5 \%$ and a 5 -year survival rate of $40.1 \%$ (Figure 2A). Once discharged from hospital, the outcome improved significantly: 1-year survival after hospital discharge was $94.2 \%$, 5-year survival was $86.5 \%$. As in HANDOUT, dialysis dose had no impact on survival (28.6\% [intensified dialysis $\{\mathrm{ID}\}$ ] vs $31.9 \%$ [standard dialysis $\{\mathrm{SD}\}])$. Mean survival was $558 \pm 825$ days vs $629 \pm 845$ days, $P=0.52$; relative risk: 1.02 vs 0.97 (ID vs SD). All data were

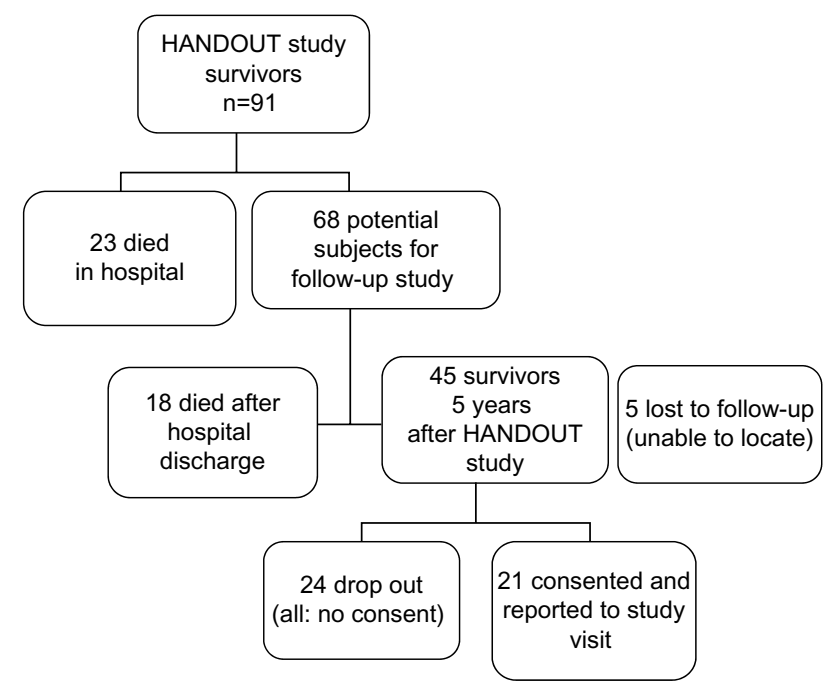

Figure I Patient flow and outcome from HANDOUT study to the 5-year followup study.

Abbreviation: HANDOUT, HANnover Dialysis OUTcome.
Table I Characteristics of HANDOUT study patients at 5-year visit

\begin{tabular}{|c|c|c|}
\hline Variable & Value & $\begin{array}{l}P \text { (IED } \\
\text { vs SED) }\end{array}$ \\
\hline \multicolumn{3}{|l|}{ Baseline characteristics } \\
\hline Former HANDOUT group A/B (n/n) & $13 / 8$ & \\
\hline \multicolumn{3}{|l|}{$\operatorname{Sex}(n[\%])$} \\
\hline Female & $7[33.3]$ & ns \\
\hline Male & $14[67.7]$ & ns \\
\hline Age (mean \pm STDV) & $51.9 \pm 14.2$ & ns \\
\hline BMI (mean \pm STDV) & $25.8 \pm 4.7$ & ns \\
\hline \multicolumn{3}{|l|}{ Blood pressure RR (mean \pm STDV) } \\
\hline Systolic/diastolic & $132.2 \pm 18 / 81.8 \pm 13$ & ns \\
\hline \multicolumn{3}{|l|}{ Renal function parameters } \\
\hline S-creatinine $(\mu \mathrm{mol} / \mathrm{L} ;$ mean \pm STDV $)$ & I I0/49.0 & ns \\
\hline S-urea (mmol/L; mean [STDV]) & $7.7 \pm 3.0$ & ns \\
\hline S-protein (g/L; mean \pm STDV) & $7.1 \pm 4.5$ & ns \\
\hline S-phosphate (mmol/L; mean \pm STDV) & $1.02 \pm 0.1$ & ns \\
\hline S-calcium (mmol/L; mean \pm STDV) & $2.35 \pm 0.1$ & ns \\
\hline $\begin{array}{l}24 \text { hours urine } C C R(\mathrm{~mL} / \mathrm{min} \text {, mean } \pm \\
\text { STDV) }\end{array}$ & $72.9 \pm 29.2$ & ns \\
\hline $\begin{array}{l}\text { eGFR (CKD-EPI) }\left(\mathrm{mL} / \mathrm{min} / 1.73 \mathrm{~m}^{2} ; \text { mean }\right. \\
\pm \mathrm{STDV})\end{array}$ & $71.7 \pm 29.2$ & ns \\
\hline $\begin{array}{l}\text { Cystatin-C eGFR }\left(\mathrm{mL} / \mathrm{min} / \mathrm{I} .73 \mathrm{~m}^{2} ; \text { mean }\right. \\
\pm \text { STDV) }\end{array}$ & $76.8 \pm 35.4$ & ns \\
\hline $\begin{array}{l}\text { Urine volume }(\mathrm{mL} / 24 \text { hours; mean } \pm \\
\text { STDV) }\end{array}$ & $2,54 I \pm I, I 32$ & ns \\
\hline 24 hours proteinuria (mg; mean \pm STDV) & $101 \pm 84$ & ns \\
\hline $\mathrm{Hb}(\mathrm{g} / \mathrm{dL} ;$ mean $\pm \mathrm{STDV})$ & $14 \pm 1.4$ & ns \\
\hline \multicolumn{3}{|c|}{ Renal ultrasound; $n=19$ (no subgroup statistics) } \\
\hline Renal volume (mL; mean \pm STDV) & $143.4 \pm 42.5$ & \\
\hline \multicolumn{3}{|l|}{ Chronic renal lesions (n [\%]) } \\
\hline Total & 15 [79] & \\
\hline Parenchymal condensation & II [58] & \\
\hline Cysts & II [58] & \\
\hline Calcification & $5[26]$ & \\
\hline Scarring & $4[2 I]$ & \\
\hline Gross scarring & $3[16]$ & \\
\hline Atherosclerosis (n [\%]) & $9[47]$ & \\
\hline RI (mean \pm STDV) & $0.695 \pm 0.06$ & \\
\hline \multicolumn{3}{|c|}{ Electrocardiogram; $n=16$ (no subgroup statistics) } \\
\hline Arrhythmia (n [\%]) & $5[31]$ & \\
\hline Repolarization disturbance (n [\%]) & 16 [63] & \\
\hline Signs of past infarction ( $\mathrm{n}[\%]$ ) & $4[25]$ & \\
\hline Most frequent: left type (n [\%]) & $6[38]$ & \\
\hline
\end{tabular}

Abbreviations: BMI, body mass index; CCR, creatinine clearance rate; CKD-EPI, chronic kidney disease epidemiology collaboration; eGFR, estimated glomerular filtration rate; HANDOUT, HANnover Dialysis OUTcome; Hb, hemoglobin; RI, resistance index; RR, Riva-Rocci; STDV, standard deviation; ns, non significant; IED, intensified extended dialysis; SED, standard extended dialysis.

censored for patients whose state of life vs death $(n=5)$ or date of death in case of known death after the end of HANDOUT could not be verified $(n=14)$.

\section{Renal survival}

Renal function of the 59 surviving HANDOUT patients recovered enough to discontinue RRT within the HANDOUT 
Table 2 Comorbidity, assessed for CCS at 5 years after AKI, $\mathrm{n}=2 \mathrm{I}$

\begin{tabular}{ll}
\hline Condition & Frequency (n [\%]) \\
\hline Heart failure (any stage) & II (52) \\
Myocardial infarction & $6(29)$ \\
Moderate/severe chronic kidney disease & $6(29)$ \\
Chronic obstructive pulmonary disease & $3(14)$ \\
Peripheral atherosclerosis & $2(10)$ \\
Moderate/severe liver disease & $2(10)$ \\
Malignancy (within last 5 years) & $2(10)$ \\
Cerebrovascular disease & I (5) \\
Diabetes mellitus & $\mathrm{I}(5)$ \\
Mild liver disease & $\mathrm{I}(5)$ \\
Connective tissue disease & $\mathrm{I}(5)$ \\
\hline
\end{tabular}

Notes: Dementia, hemiplegia, metastasis of solid tumor, lymphoma, leukemia, AIDS: all $n=0$.

Abbreviations: CCS, Charlson comorbidity score; AKI, acute kidney injury.

study period. Four patients continued RRT after the end of the study period, while still being hospitalized. Of these, only one patient survived till hospital discharge. Serum (S)-creatinine at 5-year follow-up was $110.2 \pm 49 \mu \mathrm{mol} / \mathrm{L}$;
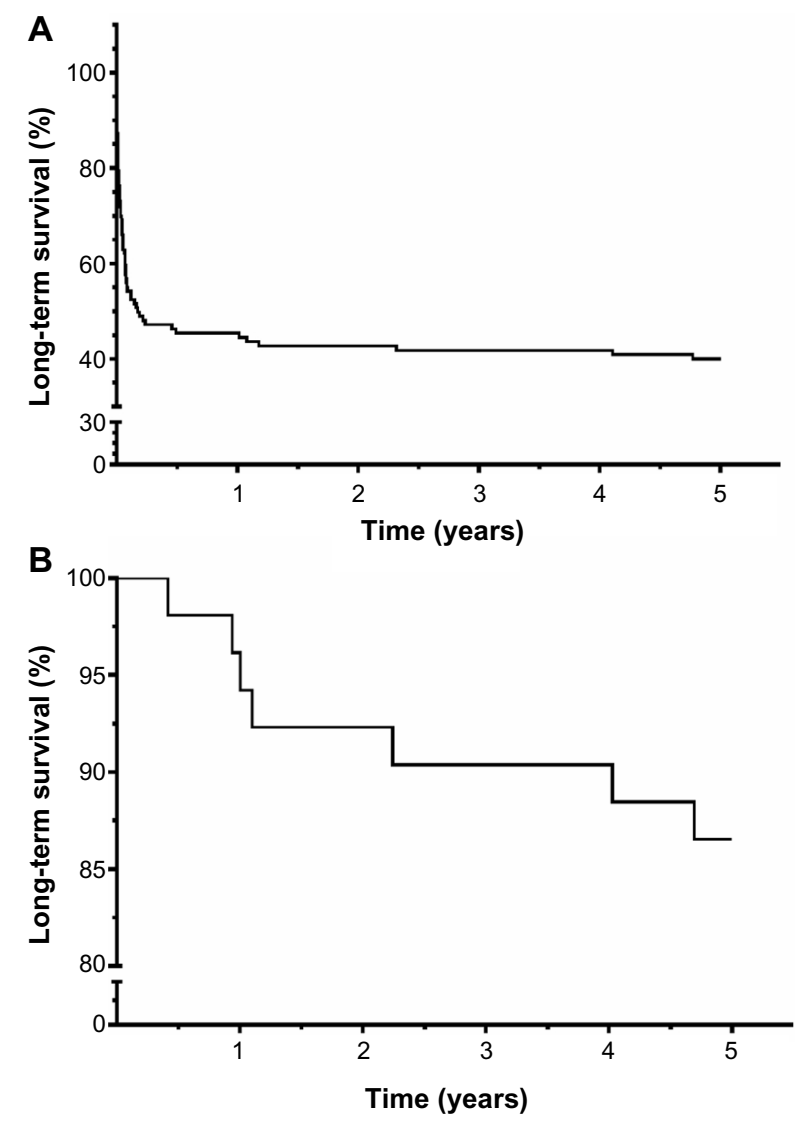

Figure 2 (A) Long-term survival after illness and AKI/RRT. (B) Survival proportions of hospital discharged patients after critical illness with AKI/RRT.

Notes: Survival proportions plotted by Kaplan-Meier curves. (A) Long-term survival of patients suffering from severe AKI with need of RRT in critically ill patients. (B) Long-term survival post hospital discharge after initial survival and recovering of critical illness with AKI/RRT.

Abbreviations: AKI, acute kidney injury; RRT, renal replacement therapy. s-urea was $7.5 \pm 2.9 \mathrm{mmol} / \mathrm{L}$. The renal function according to the KDIGO 2012 chronic kidney disease (CKD) definition, ${ }^{23}$ determined by 24 hours creatinine clearance, estimated glomerular filtration rate (eGFR)-(MDRD/EPI), and Cystatin-C-eGFR, recovered well after 5 years and averaged CKD stage G2A2 with a mean (4_method) $_{\text {GFR of }}$ $72.6 \pm 30 \mathrm{~mL} / \mathrm{min} / 1.73 \mathrm{~m}^{2}$. Twenty-four-hour urine was collected from 16 participants and examined for proteinuria. Of these, $25.0 \%$ of participants did not have proteinuria, whereas $68 \%$ had mild-proteinuria $\geq 30-<300 \mathrm{mg} / \mathrm{d}$. Only one person presented with advanced proteinuria, which was still borderline at $320 \mathrm{mg} / \mathrm{d}$. Mean proteinuria was $89 \pm 84$ $\mathrm{mg} / \mathrm{d}$ (Figure 2). Compared to the oldest S-creatinine value available after HANDOUT, but prior to HANDOUT 5-year follow-up, mean S-creatinine decreased by $\sim 25 \%$. This trend was, however, not significant and occurred due to one outlier and incomplete data $(110.2 \pm 49.5[\mathrm{n}=21]$ vs $154.4 \pm 107.6$ [n=11], $P=0.12)$. In summary, 5 years after AKI, $40.4 \%$ had CKD (GFR $<60 \mathrm{~mL} / \mathrm{min} / 1.73 \mathrm{~m}^{2}$ ) (Figure 3). Only one patient still required hemodialysis $(0.6 \%)$. Renal ultrasound (patho-) morphology was examined in 19 follow-up patients. Of these, $\sim 80 \%$ had a pathological finding, with parenchymal condensation and renal cysts being the most frequent (each $\mathrm{n}=11$ [58\%]) (Table 2). Resistance index was high normal, with a mean of $0.70 \pm 0.0$ for either kidney, indicating slightto-moderate interstitial fibrosclerosis. Atherosclerosis of abdominal vessels (47\%) or aortal sclerosis (37\%) showed a high prevalence. Laboratory parameters indicating advanced stages of CKD did not vary widely; potassium, sodium, calcium, and phosphorus averaged within the normal range, as

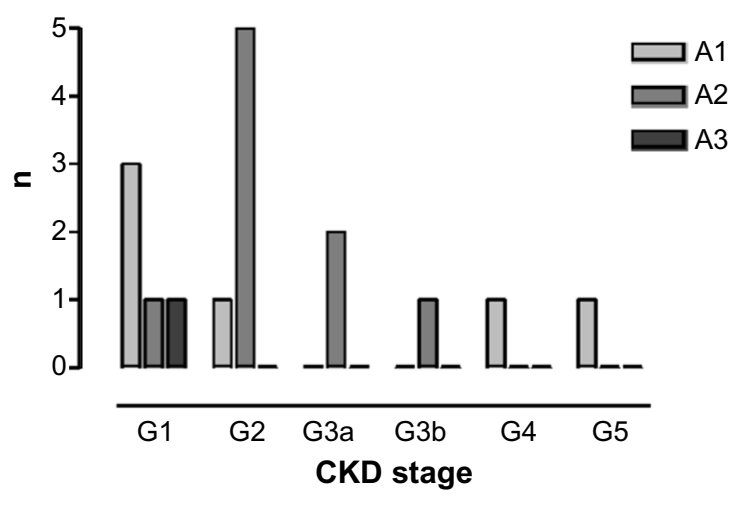

Figure 3 Renal function \% years after AKI/RRT, n=16 (according to KDIGO-20I2 classification).

Notes: Kidney function 5 years after surviving critical illness with RRT/AKI. CKD definition according to KDIGO 20I2. Mean of eGFR (Cystatin-C GFR, MDRD, CKD-EPI) and creatinine clearance and proteinuria measured from 24-hour urine collections. Classification according to KDIGO-20I2 recommendation.

Abbreviations: $A K I$, acute kidney injury; RRT, renal replacement therapy; CKD, chronic kidney disease; CKD-EPI, chronic kidney disease epidemiology collaboration; eGFR, estimated glomerular filtration rate; KIDGO, kidney disease improving global outcomes; MDRD, modification of diet in renal disease. 
did hemoglobin and venous acid-base determination (data not shown). Mean blood pressure was $132 \pm 17 / 81 \pm 13 \mathrm{mmHg}$. Eighty-six percent of the patients received antihypertensive drugs, with $\beta$-blockers and diuretics most often being prescribed (each 61\%), followed by angiotensin-converting enzyme inhibitors (39\%) and angiotensin-receptor-blockers (11\%).

\section{Morbidity}

Mean hospital admission frequency during the 5 years following HANDOUT was $1.90 \pm 2.4$, which adds up to 0.38 hospital admissions/per patient year (range: 0-10). Approximately 33\% did not have any hospital stay after initial discharge. The total number of hospital stays was 40 , with $25 \%$ of these being related to the underlying disease that contributed to the pathogenesis of the initial AKI. Numbers of comorbid conditions averaged 2.38 \pm 1.72 per patient (range 0-6), and the most frequent were heart failure of any stage $(\mathrm{n}=11$ [52\%]), CKD, and myocardial infarction (each $n=6$ [29\%]) (Table 2). Age-adjusted CCS was $3.33 \pm 2.08$, resulting in an age-adjusted expected 1 -year mortality of $52 \%$.

\section{Health status and QoL}

SF- $36^{\mathrm{TM}}$ is a health survey with 36 questions. It yields an 8 -scale profile of functional health and well-being scores, as well as psychometrically based physical and mental health summary measures and a preference-based health utility index. Figure 4A summarizes the reports for the physical health status. The patients were able to cope with usual daily self-sustaining physical activity with much confidence. They had little restrictions with activities requiring extensive strength. Physical activity was seldom affected by pain interference, and the physical status did not hinder the completion of tasks focused on self-sustaining daily activities. The patients noticed deterioration in general health compared to their pre-ICU life, but on the other hand, it seemed not to be a dynamic process of continuously decreasing vigor. The general well-being translates to a positive emotional status (Figure 4B). The time spent in social activity was limited, but the quality of the social experience (="social extent") was not. The former critical disease had little impact on mental health, and a positive perception of the own unrestricted emotional role dominated. However, as can be seen by the values for levels of vitality, to maintain the positive attitude, much energy was required. This seemed to tire the patients, thus reducing the estimates for vitality to comparably low levels. In summary, neither physical health nor QoL was largely reduced compared to the standard population. Reintegration into society was sufficient, with little interindividual variation. Feeling of exertion contributed to a subjective estimate of low general health, which, in contrast, did not find a specific accomplice in restriction of physical functioning.

\section{QALY and treatment costs}

The median SF-36 ${ }^{\mathrm{TM}}$ index score was 0.657 (0.69 physical health; 0.66 mental health). SF-36 ${ }^{\mathrm{TM}} / \mathrm{QALY}$ after 5 years was 3.365 ([physical health 3.44+ mental health 3.29]/2; $\mathrm{n}=19$ ). A total of 1,600 dialysis treatments had been delivered during the HANDOUT study period to treat the 156 patients. Calculating $€ 200$ per treatment, total dialysis expenses were $€ 320,000$. Hence, dialysis costs for each HANDOUT participant per gained QALY after 5 years added up to $€ 60,959$ ([€320,000/3.365 QALY]/156) (excluding the cost for one patient requiring maintenance hemodialysis after hospital discharge). Approximating 30\% long-term 5-year survivors (Figure 1), the expected and to-be-invested dialysis expenses during the 28-day HANDOUT study treatment period for each long-term survivor increases by three- to four fold to a maximum of $€ 2,212$ (€20,000/3.365 QALY/43). Presuming the five "lost to follow-up" patients (Figure 1) as survivors, this sum decreases to $€ 1,981$. We conclude that $\sim 30 \%$ of the total money allocated to RRT to treat severe AKI in ICU patients will eventually be spent directly on achieving longterm survival of individual patients who, after all, will gain an acceptable QoL after 5 years.

\section{Discussion}

\section{Survival}

The HANDOUT 1-yearsurvival of $44.6 \%$ compares well to $37 \%$ reported by $\mathrm{Ng}$ et $\mathrm{al},{ }^{24}$ in a study including patients with preexisting CKD. In contrast, Carl et $\mathrm{al}^{25}$ reported only $24.6 \%$ 1 -year survival in a septic study population with AKI. The in-hospital mortality was reported as 38\%-69\% in a recent review, ${ }^{26}$ which matches with our result of $\sim 60 \%$. Our longterm outcome is slightly better compared to former studies, which reported $62 \%-84.5 \%$ long-term mortality, ${ }^{10,11,27,28}$ and is in accordance with Luckraz et al's study, ${ }^{17}$ who reported a 5 -year mortality of 48\%. Different study populations, treatment protocols, causes, and definitions of AKI or "long-term surviving" make comparative analysis of survival rates difficult at this point.

\section{Renal survival}

Renal survival in our study was excellent. Sixty percent of participants did not have any reduction of kidney function; 
A

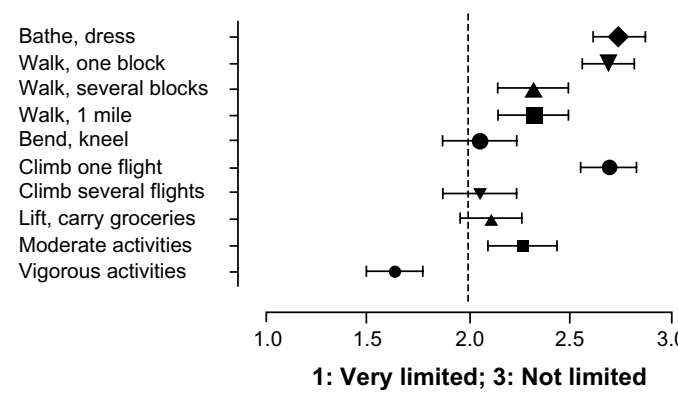

Bodily pain

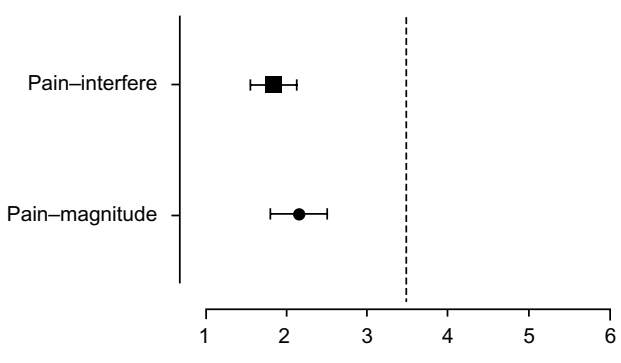

1: None; 6: Very severe

B

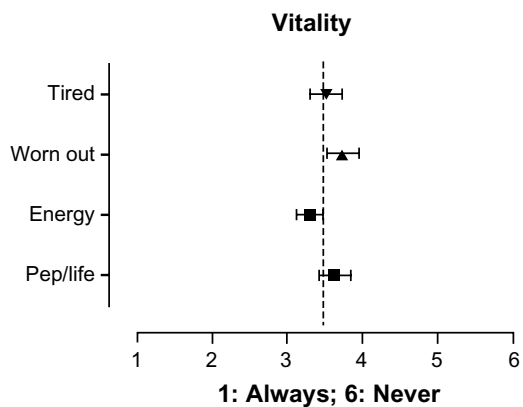

Emotional role

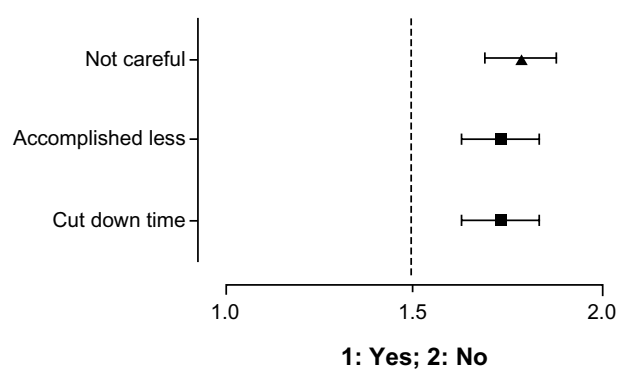

Physical role

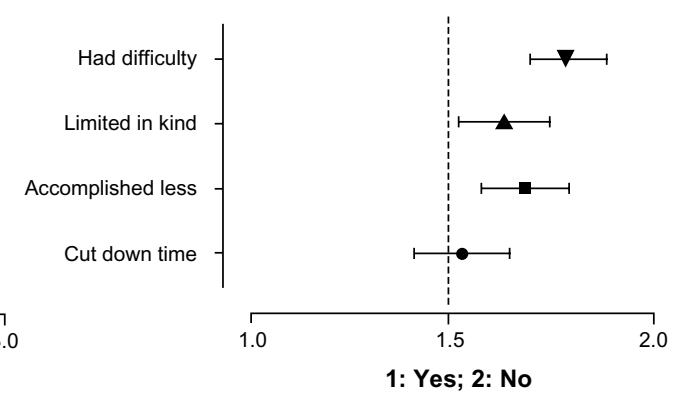

General health

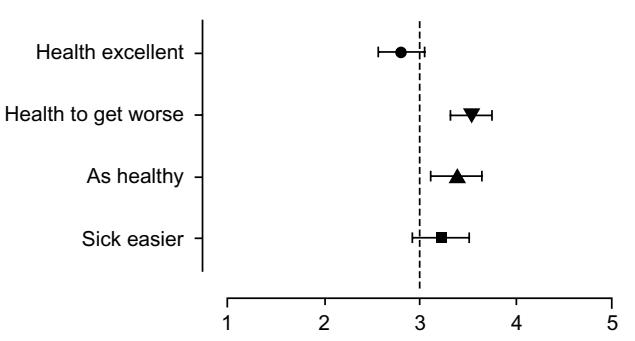

1: Very right; 5 : Very wrong

Social functioning

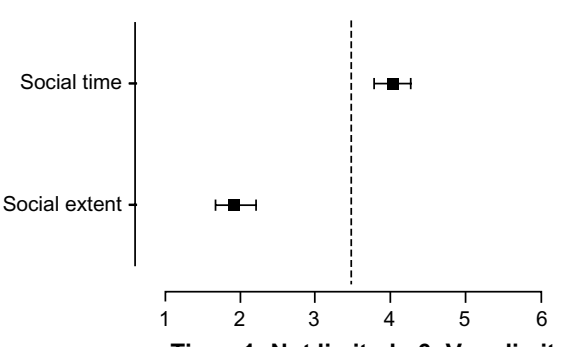

Time: 1: Not limited; 6: Very limited Extent: 1: Very limited; 6: Not limited

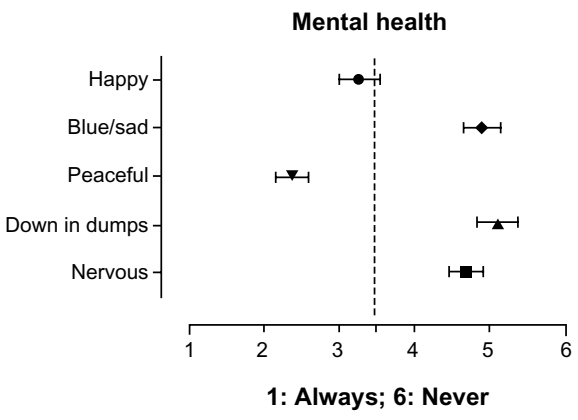

Figure 4 Self-assessed quality of life 5 years after critical illness with AKI/RRT measured by SF-36 ${ }^{\text {Th }}$ questionnaire, (A) physical health, (B) mental health. Notes: (A) SF-36 ${ }^{\text {TM }}$, quality of life: physical health, $n=19$. (B) $S F-36^{\text {Th }}$, quality of life: mental health, $n=19$. Mean \pm STDV.

Abbreviations: AKI, acute kidney injury; RRT, renal replacement therapy; STDV, standard deviation; SF-36 ${ }^{\mathrm{TM}}$, 36 -item short form health survey.

the others mostly had a mild reduction of the eGFR. Only one patient (who had had initial nonrecovery) required maintenance hemodialysis. Other studies on long-term recovery of renal function after AKI reported varying results. Schiffl and Fischer ${ }^{11}$ reported $3 \%$ end-stage renal disease patients and $13 \%$ patients with $\mathrm{CKD} .{ }^{11}$ Others reported retrospectively a long-term maintenance dialysis rate after AKI of $2 \%{ }^{17}$ to $\sim 10 \%{ }^{14,28}$ These studies found CKD prevalence of $41 \%-44 \%$ among their participants, which matches well with our findings. Therefore, the majority of surviving patients after severe AKI requiring RRT recover fully to normal kidney function, a significant minority of $\sim 40 \%-45 \%$ seem to achieve a partial 
recovery to moderate $\mathrm{CKD}$, and very few patients fail to recover at all and remain on or become dependent on chronic dialysis, which fit well with our findings. Also, markers for advanced CKD, such as renal anemia, Astrup, or mineral bone disease markers were not relevantly pathological in our study group. However, the average renal volume was slightly reduced, indicating chronic damage. The mean renal resistance index in our study was 0.7 , which according to Sugiura and Wada $^{29}$ is predictive for progressing CKD.

\section{Morbidity}

As has been demonstrated in the PRISCUS trial, rising health care cost can be expected with an increasing CCS. ${ }^{30}$ The CCS has also been used to examine health care cost in advanced renal patients. ${ }^{31}$ The high CCS in our patients $(2.19 \pm 1.4) 5$ years after AKI documents a prevalent high risk of future mortality. Ageadjusted 1 -year mortality was $52 \%$. Sixty-seven percent of our study patients presented multimorbidity ( $\geq 2$ comorbid conditions). This burden of disease is significantly higher compared to the $58.6 \%$ of a large elderly German population (aged 65-94 years) who had not been suffering from $\mathrm{AKI} .{ }^{32}$ van Oostrom et $\mathrm{al}^{33}$ demonstrated that certain comorbid conditions occurred in clusters (eg, cardio/metabolic cluster), and thus specific subgroups of patients within these clusters will, independent from age, have rates of multimorbidity up to $70 \%$, similar to our findings. For example, patients with Acute Kidney Injury Network (AKIN) II-III after coronary angiography have an increased risk of hospital readmission, with a significant hazard ratio (HR) of 3.6 for myocardial infarction and an even higher HR for heart failure (HR: 11.9). As depicted in Table 2, findings compare very well to the variety of comorbid conditions found in our post-HANDOUT patients (Table 2). Interestingly, besides relapsed AKI (HR: 16.3), James et $\mathrm{al}^{34}$ did not find any past AKI-dependent causes for hospital readmission. The risk of hospital admission is related to the stage of CKD. In patients with a GFR $>60 \mathrm{~mL} / \mathrm{min}$, the rate of hospital admissions was 13.5 per 100 patient years, which is approximately only half the rate found in our post-AKI patients. ${ }^{35}$ Heart failure and coronary heart disease are the most frequent comorbidities in our patients and probably the main contributors to future morbidity and mortality. In general, CKD patients have high rate of cardiovascular disease ( $46 \%)$, and CKD is a well-known, independent cardiovascular risk factor ${ }^{36,37}$ Therefore, reduction of the cardiovascular risk should be the key element in medical treatment survivors of severe AKI.

\section{QoL}

Our SF-36 ${ }^{\mathrm{TM}}$ results indicate that the long-term survivors after critical illness with severe AKI have a good QoL, a satisfactory emotional role, and only limited physical restrictions (Figure 4A and B). Van Berendoncks et $\mathrm{al}^{38}$ reported self-assessed health from survivors 1-2 years after AKI. These patients were $\sim 7 \%$ worse concerning physical health, but $5 \%$ better concerning mental health compared with our data, thus confirming the general trend seen in our patients. Similar results were also seen by Delannoy et $\mathrm{al}^{39}$ as early as 6 months after surviving AKI requiring RRT in the ICU. ${ }^{39}$ Abelha et $\mathrm{al}^{40}$ on the other hand indicated otherwise. These authors investigated QoL by SF-36 ${ }^{\mathrm{TM}}$ in patients 6 months after AKI. ${ }^{40}$ They reported a severely disturbed emotional role and up to $\sim 30 \%$ reduced subscale results compared to our data. However, as we have demonstrated, out-of-hospital death toll remains high especially during the first year after hospital discharge ( $43 \%$ ) versus only approximately $14 \%$ within the next following 4 years each. Hence, 6 months after discharge, follow-up time simply seems too short to reliably determine long-term QoL after severe AKI. Emotional recovery needs special attention: Samuelson et $\mathrm{al}^{41}$ identified stressful experiences of ventilated patients, which led to high levels of anxiety and depression 2 months after discharge from ICU. Individual stress-coping strategies play an important role. Patients not in distress had a significantly higher perception of their capabilities and ability to acknowledge a change in their interpersonal relations. ${ }^{42}$ In addition, the use of certain standard ICU medication has an impact on psychological outcome (ie, vasopressors: anxiety; benzodiazepines: depression; steroids: better physical QoL). ${ }^{43}$ Awareness of these relations should influence therapeutic strategies on ICU to convey positive aspects in psychological recovery after critical disease. ${ }^{44}$

Regarding QoL, we deduce from our 5-year QoL data that there are only slight restrictions in managing daily life because of episodes of pain, and the overall mental state indicates general emotional well-being. In contrast, the patients claim the highest magnitude of difficulties caused by rather poor bodily resilience, but this is obviously well tolerated mentally. We conclude that after a very serious life-threatening condition, the patients cope by changing the mental perception of prevalent physical restrictions, by developing a more optimistic and relaxed attitude toward their personal situation.

\section{QALY and treatment costs}

Our findings correspond well to recent EQ-5D index score data from Laukkanen et al, ${ }^{45}$ who reported QALY after severe AKI 5 years after hospital discharge as 3.38 and calculated $€ 34,000 / \mathrm{Q} A L Y$ cost utility for hospital survivors. Our data show that with approximately $€ 2,100$ RRT 
cost per QALY hospital-survivor, the cost needed to treat AKI with Genius ${ }^{\mathrm{TM}}$-SLED is only a small fraction of the total ICU and in-hospital treatment cost. However, because of the multimorbidity, the severity of the disease, and the high mortality, AKI/RRT patients in ICU in general, range among the most costly. ${ }^{46}$ Cost-effectiveness of critical care medicine was analyzed in a meta-analysis of 19 studies in 2006. The authors presumed that many studies report a favorable cost-effectiveness, with cost utility $<\$ 50,000$ US/QALY (2013: <€38,400), a sum that already will be exceeded in critically ill patients with AKI/RRT and just average prognosis. ${ }^{47}$ Risk scores, as those recently published for AKI/RRT for example, could in principle be used to base clinical decisions on issues of cost-effectiveness and prospective QALY-based cost utility calculations. ${ }^{48}$ However, in general agreement with our findings, Rawles ${ }^{49}$ discussed as early as 1989 that "the use of QALYs for the comparison of treatments [...] leads to serious undervaluation of life and treatments that prolong it".

\section{Limitations}

Our findings are limited by the small set of patients, because some of the HANDOUT survivors could not be located. However, as it is not possible to determine why these patients were lost to follow-up, we cannot conclude if a possible bias affects our study in a negative or positive way. Unfortunately, we could not obtain the complete data from all surviving patients owing to participants refusing to provide consent. Of note, some of the survivors who did not provide consent did not recall having been affected by a kidney injury 5 years "ago" at all. Missing data of such obviously healthy patients certainly led to a negative bias within our analysis.

\section{Conclusion}

Long-term surviving ICU patients after severe AKI have a good recovery of renal function and mental health and an acceptable recovery of physical health. They mostly achieve social reintegration and a satisfactory QoL. Only relatively moderate expenses per QALY need to be spent for RRT per individual within the frame of costly ICU treatments. However, because of an increased cardiovascular risk, life expectancy in survivors of AKI and critical illness is probably compromised. Regular follow-up examinations should therefore be recommended by the attending physicians at hospital discharge. For intensivists, special emphasis on reducing situation-medication-driven patient distress during the acute ICU treatment may help to achieve faster and more complete emotional recovery after hospital discharge. It is important for future studies to ensure a sufficiently extended time period for physical and mental recovery before assessing the complex rehabilitation process. However, to our knowledge, prospective repetitive data are yet to be acquired (ie, yearly follow-up assessments for extended periods) to determine the length of such a period.

\section{Acknowledgments}

The data were partly presented as abstracts at the Meeting of the German Society of Nephrology and the Renal Week of the American Society of Nephrology in 2009, the ERAEDTA meeting in 2010, and at the Meeting of the German Society of Nephrology 2012.

We are grateful to Mr Chris Heidemanns (OPTIMACTION, Germany) and Mr Matthew Rogers (International School of Rheinfelden, Switzerland) for reviewing parts of the manuscript regarding the use of language.

\section{Author contributions}

All authors contributed toward data analysis, drafting and critically revising the paper, and agree to be accountable for all aspects of the work.

\section{Disclosure}

The authors report no conflicts of interest in this work.

\section{References}

1. Uchino S, Kellum JA, Bellomo R, et al. Acute renal failure in critically ill patients: a multinational, multicenter study. JAMA. 2005;294(7): 813-818.

2. Hoste EA, Schurgers M. Epidemiology of acute kidney injury: how big is the problem? Crit Care Med. 2008;36(4 Suppl):S146-S151.

3. Dasta JF, Kane-Gill SL, Durtschi AJ, Pathak DS, Kellum JA. Costs and outcomes of acute kidney injury (AKI) following cardiac surgery. Nephrol Dial Transplant. 2008;23(6):1970-1974.

4. Chertow GM, Burdick E, Honour M, Bonventre JV, Bates DW. Acute kidney injury, mortality, length of stay, and costs in hospitalized patients. J Am Soc Nephrol. 2005;16(11):3365-3370.

5. Hamel MB, Phillips RS, Davis RB, et al. Outcomes and cost-effectiveness of initiating dialysis and continuing aggressive care in seriously ill hospitalized adults. SUPPORT Investigators. Study to Understand Prognoses and Preferences for Outcomes and Risks of Treatments. Ann Intern Med. 1997;127(3):195-202.

6. Desai AA, Baras J, Berk BB, et al. Management of acute kidney injury in the intensive care unit: a cost-effectiveness analysis of daily vs alternateday hemodialysis. Arch Intern Med. 2008;168(16):1761-1767.

7. Coca SG, Yusuf B, Shlipak MG, Garg AX, Parikh CR. Long-term risk of mortality and other adverse outcomes after acute kidney injury: a systematic review and meta-analysis. Am J Kidney Dis. 2009;53(6):961-973.

8. Barrantes F, Tian J, Vazquez R, Amoateng-Adjepong Y, Manthous CA. Acute kidney injury criteria predict outcomes of critically ill patients. Crit Care Med. 2008;36(5):1397-1403.

9. Faulhaber-Walter R, Hafer C, Jahr N, et al. The Hannover Dialysis Outcome study: comparison of standard versus intensified extended dialysis for treatment of patients with acute kidney injury in the intensive care unit. Nephrol Dial Transplant. 2009;24(7):2179-2186. 
10. Ahlstrom A, Tallgren M, Peltonen S, Rasanen P, Pettila V. Survival and quality of life of patients requiring acute renal replacement therapy. Intensive Care Med. 2005;31(9):1222-1228.

11. Schiffl H, Fischer R. Five-year outcomes of severe acute kidney injury requiring renal replacement therapy. Nephrol Dial Transplant. 2008;23(7):2235-2241.

12. Uchino S, Bellomo R, Morimatsu H, et al. Continuous renal replacement therapy: a worldwide practice survey. The beginning and ending supportive therapy for the kidney (B.E.S.T. kidney) investigators. Intensive Care Med. 2007;33(9):1563-1570.

13. Morgera S, Schneider M, Neumayer HH. Long-term outcomes after acute kidney injury. Crit Care Med. 2008;36(4 Suppl):S193-S197.

14. Gallagher M, Cass A, Bellomo R, et al. Long-term survival and dialysis dependency following acute kidney injury in intensive care: extended follow-up of a randomized controlled trial. PLoS Med. 2014;11(2):e1001601.

15. Jones CA, McQuillan GM, Kusek JW, et al. Serum creatinine levels in the US population: third National Health and Nutrition Examination Survey. Am J Kidney Dis. 1998;32(6):992-999.

16. Bhandari S, Turney JH. Survivors of acute renal failure who do not recover renal function. QJM. 1996;89(6):415-421.

17. Luckraz H, Gravenor MB, George R, et al. Long and short-term outcomes in patients requiring continuous renal replacement therapy post cardiopulmonary bypass. Eur J Cardiothorac Surg. 2005;27(5):906-909.

18. Gopal I, Bhonagiri S, Ronco C, Bellomo R. Out of hospital outcome and quality of life in survivors of combined acute multiple organ and renal failure treated with continuous venovenous hemofiltration/hemodiafiltration. Intensive Care Med. 1997;23(7):766-772.

19. Maynard SE, Whittle J, Chelluri L, Arnold R. Quality of life and dialysis decisions in critically ill patients with acute renal failure. Intensive Care Med. 2003;29(9):1589-1593.

20. Ware JE Jr, Sherbourne CD. The MOS 36-item short-form health survey (SF-36). I. Conceptual framework and item selection. Med Care. 1992;30(6):473-483.

21. McHorney CA, Ware JE Jr, Raczek AE. The MOS 36-Item Short-Form Health Survey (SF-36): II. Psychometric and clinical tests of validity in measuring physical and mental health constructs. Med Care. 1993;31(3):247-263.

22. Karlsson S, Ruokonen E, Varpula T, Ala-Kokko TI, Pettila V; Finnsepsis Study Group. Long-term outcome and quality-adjusted life years after severe sepsis. Crit Care Med. 2009;37(4):1268-1274.

23. Group IGOKCW. KDIGO clinical practice guideline for the evaluation and management of chronic kidney disease. Kidney Int Suppl. 2013;3(1):1-150.

24. Ng KP, Chanouzas D, Fallouh B, Baharani J. Short and long-term outcome of patients with severe acute kidney injury requiring renal replacement therapy. QJM. 2012;105(1):33-39.

25. Carl DE, Grossman C, Behnke M, Sessler CN, Gehr TW. Effect of timing of dialysis on mortality in critically ill, septic patients with acute renal failure. Hemodial Int. 14(1):11-17.

26. Rimes-Stigare C, Awad A, Martensson J, Martling CR, Bell M. Longterm outcome after acute renal replacement therapy: a narrative review. Acta Anaesthesiol Scand. 2012;56(2):138-146.

27. Korkeila M, Ruokonen E, Takala J. Costs of care, long-term prognosis and quality of life in patients requiring renal replacement therapy during intensive care. Intensive Care Med. 2000;26(12):1824-1831.

28. Morgera S, Kraft AK, Siebert G, Luft FC, Neumayer HH. Long-term outcomes in acute renal failure patients treated with continuous renal replacement therapies. Am J Kidney Dis. 2002;40(2):275-279.

29. Sugiura T, Wada A. Resistive index predicts renal prognosis in chronic kidney disease. Nephrol Dial Transplant. 2009;24(9):2780-2785.
30. Nagl A, Witte J, Hodek JM, Greiner W. Relationship between multimorbidity and direct healthcare costs in an advanced elderly population. Results of the PRISCUS trial. Z Gerontol Geriatr. 2012;45(2):146-154.

31. Beddhu S, Bruns FJ, Saul M, Seddon P, Zeidel ML. A simple comorbidity scale predicts clinical outcomes and costs in dialysis patients. $\mathrm{Am} \mathrm{J}$ Med. 2000;108(8):609-613.

32. Kirchberger I, Meisinger C, Heier M, et al. Patterns of multimorbidity in the aged population. Results from the KORA-age study. PLoS One. 2012;7(1):e30556.

33. van Oostrom SH, Picavet HS, van Gelder BM, et al. Multimorbidity and comorbidity in the Dutch population - data from general practices. BMC Public Health. 2012;12:715.

34. James MT, Ghali WA, Knudtson ML, et al. Associations between acute kidney injury and cardiovascular and renal outcomes after coronary angiography. Circulation. 2011;123(4):409-416.

35. Go AS, Chertow GM, Fan D, McCulloch CE, Hsu CY. Chronic kidney disease and the risks of death, cardiovascular events, and hospitalization. N Engl J Med. 2004;351(13):1296-1305.

36. Levin A. Clinical epidemiology of cardiovascular disease in chronic kidney disease prior to dialysis. Semin Dial. 2003;16(2):101-105.

37. Hostetter TH. Chronic kidney disease predicts cardiovascular disease. N Engl J Med. 2004;351(13):1344-1346.

38. Van Berendoncks AM, Elseviers MM, Lins RL. Outcome of acute kidney injury with different treatment options: long-term follow-up. Clin J Am Soc Nephrol. 2010;5(10):1755-1762.

39. Delannoy B, Floccard B, Thiolliere F, et al. Six-month outcome in acute kidney injury requiring renal replacement therapy in the ICU: a multicentre prospective study. Intensive Care Med. 2009;35(11):1907-1915.

40. Abelha FJ, Botelho M, Fernandes V, Barros H. Outcome and quality of life of patients with acute kidney injury after major surgery. Nefrologia. 2009;29(5):404-414.

41. Samuelson KA, Lundberg D, Fridlund B. Stressful memories and psychological distress in adult mechanically ventilated intensive care patients - a 2-month follow-up study. Acta Anaesthesiol Scand. 2007;51(6):671-678.

42. Grossman M, Kenny JV, Lee V, Chambers-Evans J, Godin M, McHarg L. Emotional distress in critically-injured patients three months after a potentially life-threatening accident. J Neurosci Nurs. 1999;31(3):159-173.

43. Wade DM, Howell DC, Weinman JA, et al. Investigating risk factors for psychological morbidity three months after intensive care: a prospective cohort study. Crit Care. 2012;16(5):R192.

44. Schelling G. Post-traumatic stress disorder in somatic disease: lessons from critically ill patients. Prog Brain Res. 2008;167:229-237.

45. Laukkanen A, Emaus L, Pettila V, Kaukonen KM. Five-year cost-utility analysis of acute renal replacement therapy: a societal perspective. Intensive Care Med. 2013;39(3):406-413.

46. Sznajder M, Aegerter P, Launois R, Merliere Y, Guidet B, CubRea. A cost-effectiveness analysis of stays in intensive care units. Intensive Care Med. 2001;27(1):146-153.

47. Talmor D, Shapiro N, Greenberg D, Stone PW, Neumann PJ. When is critical care medicine cost-effective? A systematic review of the costeffectiveness literature. Crit Care Med. 2006;34(11):2738-2747.

48. Demirjian S, Chertow GM, Zhang JH, et al. Model to predict mortality in critically ill adults with acute kidney injury. Clin J Am Soc Nephrol. 2011;6(9):2114-2120.

49. Rawles J. Castigating QALYs. J Med Ethics. 1989;15(3):143-147. 


\section{Publish your work in this journal}

The International Journal of Nephrology and Renovascular Disease is an international, peer-reviewed open-access journal focusing on the pathophysiology of the kidney and vascular supply. Epidemiology, screening, diagnosis, and treatment interventions are covered as well as basic science, biochemical and immunological studies. The journal welcomes

original research, clinical studies, reviews \& evaluations, expert opinion and commentary, case reports and extended reports. The manuscript management system is completely online and includes a very quick and fair peerreview system, which is all easy to use. Visit http://www.dovepress.com/ testimonials.php to read real quotes from published authors.

Submit your manuscript here: http://www.dovepress.com/international-journal-of-nephrology-and-renovascular-disease-journal 